\title{
CORRIGENDUM
}

\section{Confinements regulate capillary instabilities of fluid threads - CORRIGENDUM}

\author{
Xiaodong Chen, Chundong Xue and Guoqing $\mathrm{Hu}$ \\ doi:10.1017/jfm.2019.426, Published by Cambridge University Press, \\ 27 June 2019
}

In the published version of this article (Chen, Xue \& Hu 2019) the name of one of the authors was incorrect and should have appeared as 'Guoqing Hu'. This has been corrected online and in print.

\section{REFERENCE}

Chen, X., Xue, C. \& HU, G. 2019 Confinements regulate capillary instabilities of fluid threads. J. Fluid Mech. 873, 816-834. 